\title{
Infraclavicular block in a preterm neonate with congenital amputation.
}

\author{
Morillas-Sendín P', Gonzalez-Moraga Fl', Ruiz-Abascal R², Salvatierra D², Ordoñez S', Ortega I². \\ I Gregorio Marañón University General Hospital, Dept of Anaesthesiology \& Intensive Care, Madrid, Spain, \\ ${ }^{2}$ La Moraleja University Hospital, Dept of Anaesthesiology, Madrid, Spain, \\ ${ }^{3}$ La Moraleja University Hospital, Dept of Plastic Surgery, Madrid, Spain.
}

\section{Background}

Brachial plexus blockade is a well-established technique in upper-limb surgery and can be performed by various approaches in children. In paediatric patients, the axillary route is usually preferred to infraclavicular approaches because of safety considerations. Nevertheless, there is no much experience about the infraclavicular block in preterm neonates.

\section{Case report}

We present the case of a preterm infant ( 30 weeks, twin pregnancy), female, and very low birth weight ( $1.47 \mathrm{~kg})$ with congenital amputation (radial and ulnar hemimelia). She also developed a respiratory distress syndrome due to hyaline membrane disease treated with supplementary oxygen. As aplasia/hypoplasia is usually associated with congenital diseases, a complete examination (cardiac, abdominal and cranial ultrasound) was performed; the only finding was a patent foramen ovale.

Because of exposure of the distal end of the radius, a reamputation and skin closure were considered. The baby had gradually gained weight to $1.8 \mathrm{~kg}$ and at day 21 , the surgery was planned. After explaining to the parents the benefits of regional anaesthesia in the preemie, avoiding general anaesthesia, the informed consent was obtained. Following application of routine monitors, intravenous midazolam and ketamine were administered for sedation.

The infant was placed in supine position with the shoulder abducted and the arm placed along the body. The ultrasound probe (MicroMaxx, Sonosite, L25 probe) was placed just above the coracoid process, the axillary artery and the vein were identified (Fig.I), and an echogenic needle (Stimuplex $®$, Braun) was placed in an in-plane approach. An ultrasound-guided single shot block with $0.9 \mathrm{~mL}(0.5 \mathrm{~mL} /$ $\mathrm{kg}$ ) of $0.25 \%$ bupivacaine was performed. The sedation was maintained with $2 \%$ sevoflurane thru nasal prongs, and oxygen supplementation. The preterm remained well sedated, with no movement of the upper extremity limb (Fig.2-5). She was discharged in the neonatal unit (Fig. $6)$, and the recovery was uneventful.

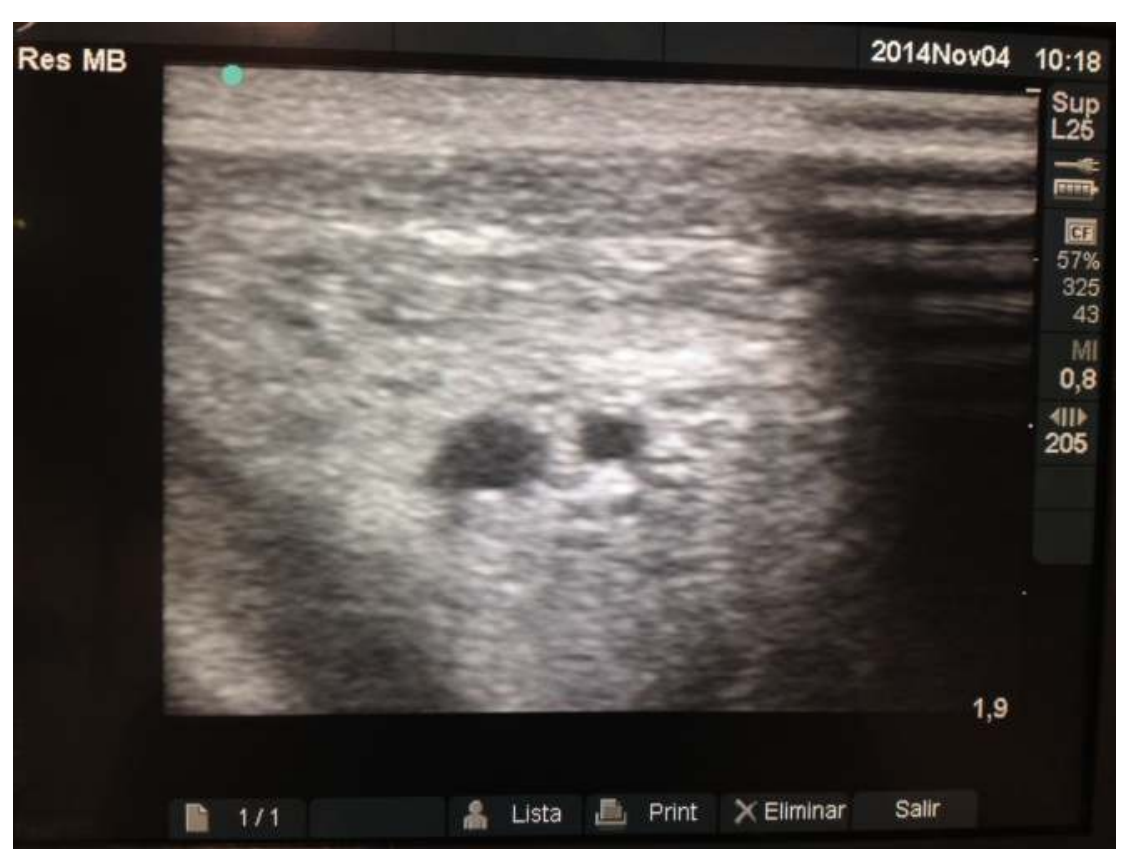

Fig. I:

Ultraosund image of the axillary artery and vein (probe placed above the coracoid process).

\section{References}

$\checkmark$ Frantz $\mathrm{CH}, \mathrm{O}$ 'Rahilly R. Ulnar HemimeMa. Artificial Limbs | 97|; 15:25-35.

$\checkmark$ Mislovic B. Multimodal analgesia including infraclavicular block in perioperative management of upper extremity amputation in neonate. Pediatric Anesthesia 201 1;21:1268-81.

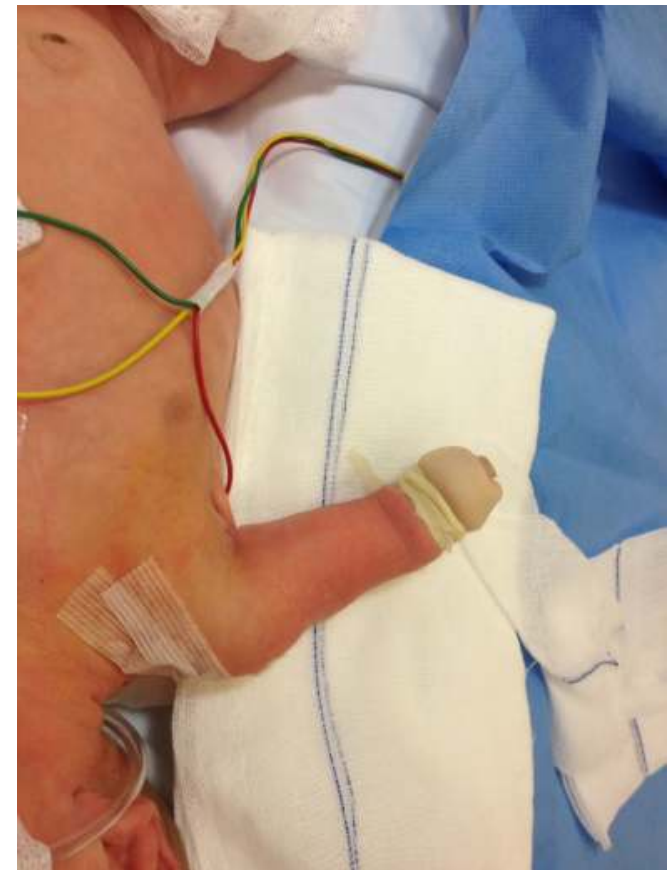

Fig. 2: Ischemia of the arm

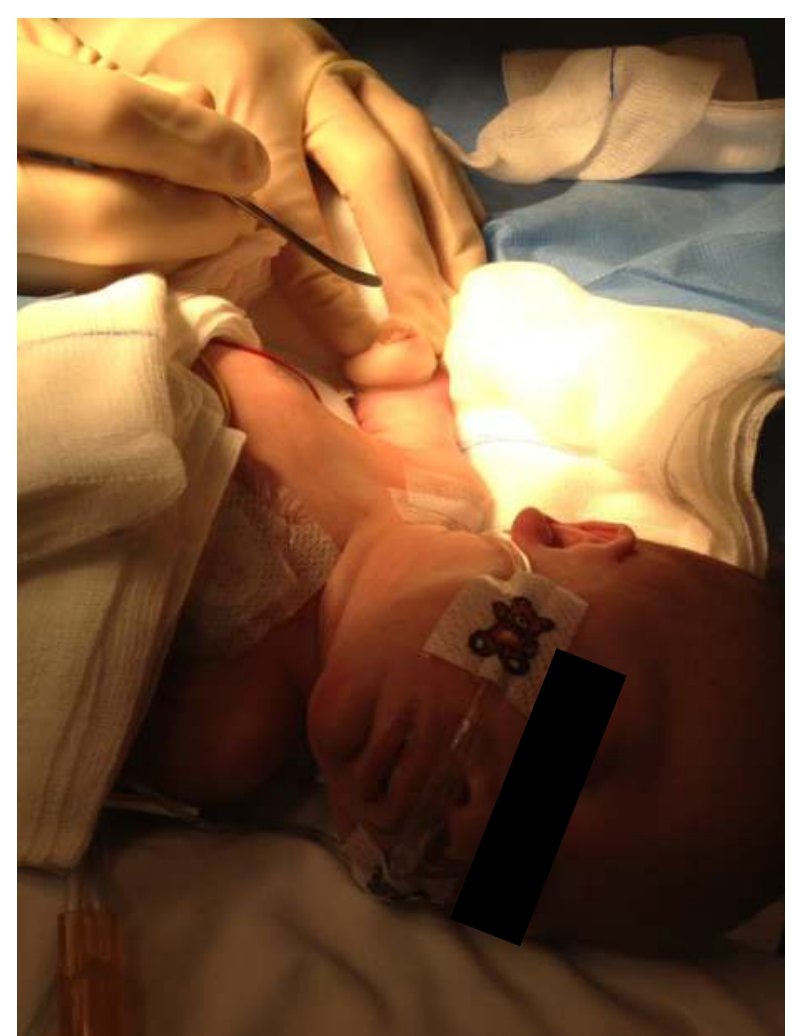

Fig. 4: Surgery

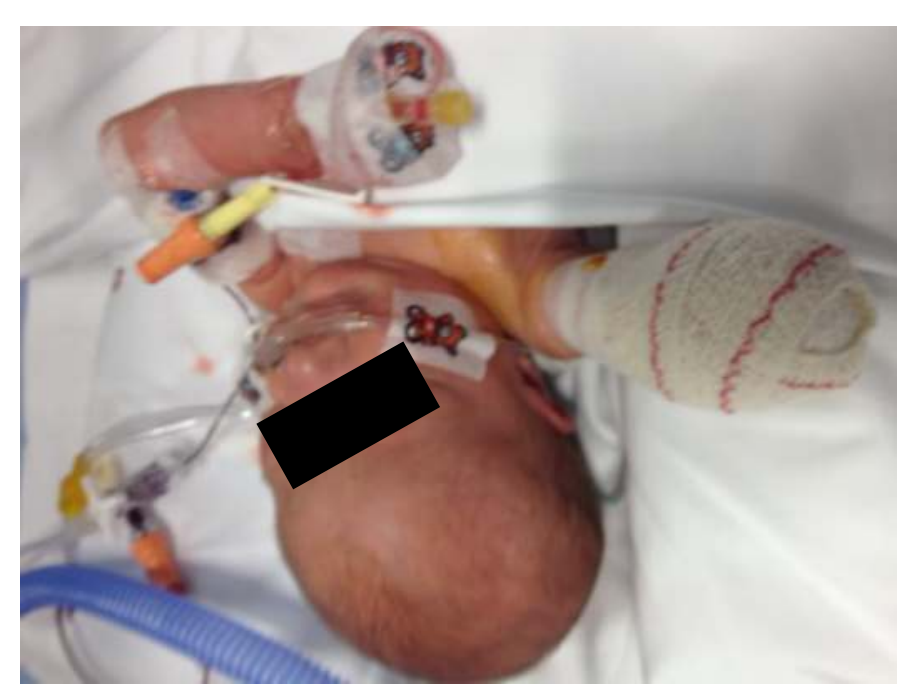

Fig. 6: Transfer to the neonatal unit

\section{Discussion}

Ultrasound visualization enabled us to perform the block under real-time image, avoiding accidental arterial punctures and intravascular injections (known during blind techniques).

Regional anaesthesia prevents complications of general anaesthesia as neurotoxicity, cardiovascular collapse, or postoperative apneas.

\section{Learning points}

In preterm neonates with low weight, regional anaesthesia can be performed under expert hands, thus avoiding general anaesthesia. Infraclavicular block is a feasible option in the intraoperative management of neonatal congenital amputation. 